\title{
The Research of Blast Resistant of Reinforcement Concrete Beams in Concrete Structures at Off-site Oil and Gas Plant
}

\author{
S. AlJasmi', N. F. Ariffin ${ }^{1,}$, M. M. Seman ${ }^{2}$ \\ ${ }^{1}$ Faculty of Civil Engineering Technology, Universiti Malaysia Pahang, 26600 Pahang, Malaysia. \\ ${ }^{2}$ College of Engineering, Department of Civil Engineering, Universiti Malaysia Pahang, 26600 Pahang, Malaysia.
}

\begin{abstract}
In the recent decades, blasts and gas explosions at the off-site of oil and gas plants have increased leading to destruction of important concrete structures, essential equipment and loss of human life. In response, structural engineers have come up with different ways of reinforcing beams of concrete structures using fiber reinforced polymers composite materials to produce blast resistant structures to minimize the impact of the blast loads, due to their unique and individual characteristics like high flexural and shear strength. This paper seeks to research the dynamic behavior, response and performance of reinforce concrete beams strengthened with Carbon Fiber Reinforced Polymer composites when subjected to blast loading. The study aims at proposing a design model of strengthening reinforce concrete beams with Carbon Fiber Reinforced Polymer in supporting concrete structures at off-site oil and gas plants against hydrocarbon explosions. Carbon Fiber Reinforced Polymer composites exhibit higher modulus of elasticity, higher energy absorption capacity, resistant to all forms of alkali and higher tensile strength compared to all other fiber reinforced polymers reinforcements and therefore the need to assess its capacity in protecting concrete structures at oil and gas plants against dynamic loads. The research will be carried out through numerical analysis using the finite element analysis computer program, ANSYS.
\end{abstract}

ARTICLE HISTORY

Received: $08^{\text {th }}$ Sept 2021

Revised: 02 ${ }^{\text {nd }}$ Nov 2021

Accepted: 03 $3^{\text {rd }}$ Nov 2021

\section{KEYWORDS}

Blast loads

Finite element analysis

Gas explosion

Hydrocarbon blast

CFRP Strengthening

\section{INTRODUCTION}

In the past decade, hazards such as accidents, earthquakes, terrorist attacks and spills of corrosive gases and liquids leading to blasts have continued to increase [1]. The record of oil and gas plants accidental events indicates that the historical off-site disasters have largely caused very significant losses in terms of destruction of important structures, human lives, environmental pollution and damage of essential equipment [2]. Reinforced concrete beams are the typical structural members used for off-site facilities like tankage for storage of raw materials and finished products, utility systems, flare systems for emergency conditions, environmental treatment units, staff and workers' quarters as well as control and communication rooms, to support concrete buildings against hazards as mentioned above [3,4]. These offsite facilities are very critical for the daily and continued operations of the plant, for emergency response [3,4], for processing and treating hydrocarbon oil and gas, supporting mechanical equipment, storing electrical and instrument cables and hydrocarbon pipelines, for communication, and as workers' quarters [5].

The functioning of off-site facilities as the main site where much of plant activities are done and their exposure to flammable and hazardous hydrocarbon materials [6], makes it an important area of study as they are considered high risk structures. Observations after numerous dangerous accidental incidents at petrochemical plants suggest that these structures and facilities need more attention [7]. Research has shown that the main modes of failure for off-site concrete structures is beam buckling or lack of blast resistant reinforcement and incase of hydrocarbon detonation or rapture of the pipelines, leaves these structures completely destroyed [6].

Additionally, Kishore et al. [8] observed that concrete material has poor tensile and compressive strength. Concrete structures can fail due to structural weaknesses, construction and design faults, structural system change, vibration settlement, overloading, and explosives or blast loads. These factors necessitate the upgrading or strengthening of concrete structures or beams. As stated by Kishore et al. [8], the main reason for reinforcing concrete beams include upgrading its shear strength to resist underestimated blast loads by increasing its load carrying capacity for higher blast loads. As a result of inadequate detailing, concrete beams fail to withstand the increased pressure and compressive forces of blast loads. Therefore, there is need to restore the reduced loading capacity of the concrete beams supporting concrete structures at off-site of oil and gas plants.

A study conducted by Nolan D.P., as cited in Yussof et al. [6] indicated that approximately 1100 insurance claims on main incidents were made worldwide in the petroleum and chemical insurance market between the year 1993 and 2013. Among these accidents reported, hydrocarbon blasts are the most hazardous incidents. Even though a hydrocarbon blast is a very rare accidental incidence, preventing occurrence of such events is not feasible with unpredictability of recurrence. Hydrocarbon explosions are considered as low probability events; however, they are potentially incidents of high consequence [6]. Gas explosion and vapour cloud explosion (VCE) are the common hazards within the oil and gas 
industry, and that they usually generate a shock or blast wave with lower peak overpressure but longer duration and greater impulse than a shock wave generated from high explosive with an equivalent energy release [1].

At most oil and gas plants, communication, control among other structures and systems have been acquired and installed without regard to hydrocarbon explosion resistance, and in many places, anchorage of these important items has frequently been insufficient or non-existent [2]. With rising cases of gas explosions, VCE, condensed phase explosion, pressure vessel explosion, and dust explosion along oil and gas plants [9], increasingly more attention need to be directed towards designing off-site facilities and structures to be safe and secure for people. Therefore, efforts to design concrete beams to resist such explosion and to keep the risk as low as possible as well as minimize the amount of structural damage are necessary [10].

Naser et al. [11] is one among the most recent study which indicates that the beams of concrete structures need to have adequate tensile strength and stiffness capacity to resist blast loading. The study further explains that connections of the structural elements need to offer a significant support to maintain the structural system integrity to absorb the explosion forces without collapsing. With the advancement of structurally effective adhesives and technology, today, fiber reinforced polymers (FRPs) are increasingly being used as effective alternative to conventional materials to offer innovative solutions for blast retrofitting and strengthening of the reinforced concrete structures owing to their lightweight, tensile strength and non-corrosive characters [12].

Many FRPs strengthening methods for RC beams under blast loads have been studied by previous researchers [1217]. However, this study mainly focuses on one of the latest concrete reinforcing material known as Carbon Fiber Reinforced Polymer (CFRP). Sorin et al. [18] indicated that CFRP systems are effective in strengthening reinforced concrete beams owing to their mechanical properties as well as economic benefit. Further, the study suggested an additional carbon fiber to be attached to the concrete beam flanges to enhance the connection performance under blast loading. Goldston [19] stated that the face of the RC beam is retrofitted with CFRP material to strengthen it in order to resist increased pressure during blast attack.

Experimental studies have also indicated that CFRP has a higher compressive strength than Basalt Fiber Reinforced Polymer (BFRP) and conventional concrete beams [20]. Recent tests have shown that unlike glass fibers, carbon fibers cannot absorb moisture and thus are resistant to acid, alkali and organic solvents [21-24]. A study by Rabinovitch \& Frostig [25] applied two varied carbon fibre strips (SikaWrap Hex-230c CFRP sheets and Sika CarboDur S1212 epoxy strips/unidirectional carbon) to examine how they would contribute in rehabilitating and improving the RC concrete beams. These carbon fiber strips were then saturated in Sikadur-330 (an epoxy resin). The study found that the CFRP strips properties differ in terms of tensile strength, elastic modulus and density.

According to other prior studies, the use of CFRP in reinforcing concrete structures has had significant impact on both shear and flexural strength of beams [26]. Some studies investigated the use of CFRP on damaged-reinforced concrete beams and found that CFRP increased the flexural strength of beams by approximately 95\% [27,28]. Furthermore, Shooshtari \& Gomar [29] examined the effect of CFRP sheets on RC beams, which were subjected to impact loading. The study revealed that strengthening of RC beams with CFRP considerably increased the impact resistance of both shear and flexure stress. Therefore, appropriate application of CFRP materials in concrete reinforcement and retrofitting leads to an increase in flexural capacity, shear strength and stiffness of a higher degree compared to other types of reinforcement polymers [30].

Even though the concept of Carbon Fiber Reinforced Polymer (CFRP) as a blast resistant material for RC beams has been widely studied under both public, government and conventional structures, in the context of RC beams, as revealed above, this concept has not been applied effectively and adequately at the off-site of oil and gas plants. In addition, the existing blast resistant design technology in the oil and gas industry has evolved from equivalent conventional static design methods to simplified dynamic design methods [31], which are suitable and safe for normal operating and precommissioning conditions that emphasize minimum obstruction to process flows [5,32]. While these designs are based on stringent safety aspects and prevention measures, they do not account for (or not safe for) abnormal loads or higher explosive loads such as hydrocarbon explosions which have higher magnitudes than ordinary operating loads, thus, causing damaging and devastating effects in terms of loss of assets, life and the environment [2,33]. Moreover, prior research has revealed that blast loading characteristics are different [34,35], thus design for normal as well as static loads does not provide or guarantee satisfactory performance against dynamic or cyclic loads such hydrocarbon explosions.

Similarly, majority of these previous studies have not included important blast resistant models such as those incorporating Carbon Fiber Reinforced Polymer for RC beams at oil and gas industry. Hence, the current research aims to simulate an RC beam model strengthened with CFRP sheets using finite element method to propose design models for RC beams at off-site oil and gas plants. These pieces of information will become the input for determining the relative importance of the proposed design through ANSYS software analysis. The FE ANSYS software is important because it will help to provide valuable insights and beam models for the actual design of blast resistant concrete structures at oil and gas plants. The ANSYS simulation environment has been extensively tested and validated in modeling FRPstrengthened structures by the authors [17,36,37], also as other researchers [13,16,35,37-42].

To facilitate the model validation, a reinforced-concrete beam configuration from Neagoe [43] was adopted and developed as a 3D model. Before modifying the model for further analysis, this research aims to compare the numerical simulation responses with the responses as reported by Neagoe [43]. 
The main and overarching aim of this study is to numerically examine CFRP as an external reinforcement material using finite element method to improve the properties, including flexural and shear capacity of RC beams of the off-site concrete structures at the oil and gas industry to resist blast loads.

\section{METHODOLOGY}

\section{Model Configuration}

Details of test specimens. A total of five RC beams based on the exact RC beam properties used at a gas plant in the gulf region, and cast and tested under four-point loading test by Neagoe [43] will be simulated in this study (refer with: Fig. 1). The variables of the test program will include the beam's behavior, tensile strength or ductility and loadingcarrying capacity. All beams have the same dimensions of $200 \mathrm{~mm}$ width, $400 \mathrm{~mm}$ height and $4500 \mathrm{~mm}$ length as well as a clear span of $4000 \mathrm{~mm}$. These beams also will have the same shear and flexural reinforcement whereby two $12 \mathrm{~mm}$ steel bars will be utilized for flexural reinforcement at the top and bottom of each RC beam. The steel stirrups of $12 \mathrm{~mm}$ were spaced at every $200 \mathrm{~mm}$ for shear reinforcement. Similarly, the basic RC beam without external reinforcement will be designed to have adequate shear strength in order to fail in flexure.

One beam will be simulated without external CFRP reinforcement. Four beams will be simulated with external CFRP reinforcement: two beams strengthened with a single CFRP sheet and another two with double CFRP sheets. All the four beams will be strengthened with the same amount of CFRP reinforcement of a fiber volume of 68-70\%, modulus of elasticity of $158 \mathrm{GPa}$, ultimate tensile strength of $2200 \mathrm{~N} / \mathrm{mm} 2$, and a density of about $1.6 \mathrm{~g} / \mathrm{cm} 3$. The laminates are $15 \mathrm{~m}$ long coils, measuring $50 \mathrm{~mm}$ width and $1.4 \mathrm{~mm}$ thickness. Concrete material properties will include Poisson's ratio of $0.22 \mathrm{~A}$ of $\mathrm{C} 35 / 45$ concrete class. All beams RC will be modeled with typical B500 S high-strength steel type with modulus of elasticity of $200,000 \mathrm{MPa}$, yield stress of $410 \mathrm{MPa}$ and a Poisson's ratio of 0.3 .

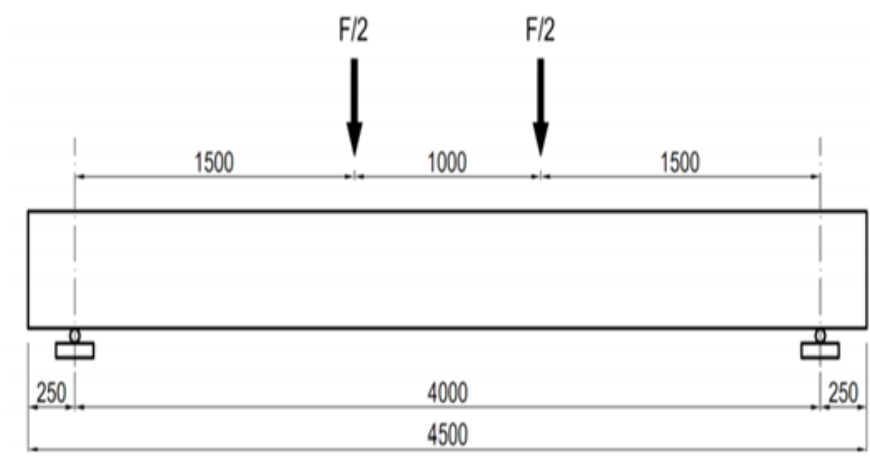

Figure 1. Loading scheme for the experimental work

\section{Finite Element Modelling}

The finite element program, ANSYS, will be used to model the RC beams, steel supports and CFRP plates. The concrete beams will be modeled as solid elements, where steel supports will be modeled as wire elements [44]. CFRP plates will be modeled as plastic, rubber, sheet or laminate elements. A typical FE model comprises of concrete, steel reinforcement, FRP system type and boundary/loading support conditions. Each of these components or materials will be appropriately modeled in this study to reflect the unique attributes associated with each of them. Based on this perspective, each component will be modeled as discussed below.

\section{Concrete Beam}

The concrete beam will be modelled using a 3D brick element known as SOLID65 in ANSYS. This element is specifically and uniquely developed to simulate rock-like materials such as concrete in this study. The attributes of this cubic element include eight nodes with three degrees of freedom at each node as well as translations in the nodal $\mathrm{x}$, $\mathrm{y}$, and $\mathrm{z}$ directions as shown in Fig. 2. The SOLID65 element applies the William and Warnke's [45] mathematical material model to model cracking in three orthogonal directions, creep, plastic deformation and crushing. 


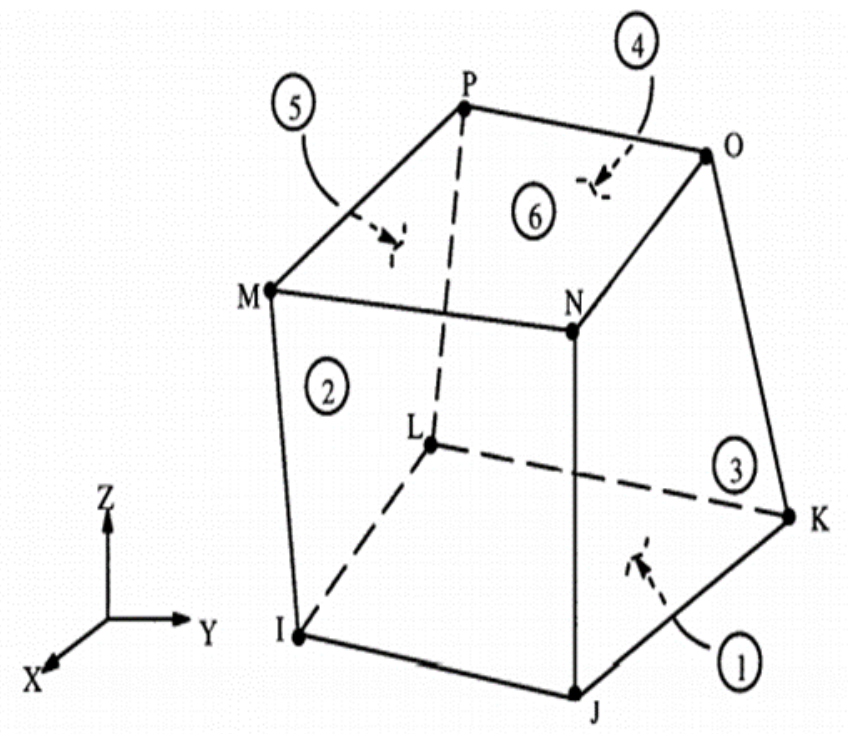

Figure 2. Reinforcement details of the beam using SOLID65 element

\section{Steel Reinforcement}

Steel or tensile reinforcement will be modeled using a spar link element designated as LINK8 in ANSYS. The spar uniaxial bar-like element is defined by two nodes with three degrees of freedom at each node which comprise of translations in the nodal $\mathrm{x}, \mathrm{y}$, and $\mathrm{z}$ directions. These reinforcing elements have the ability to simulate common nonlinear effects such as large deflection, plasticity, swelling, creep, and stress stiffening [11].

\section{FRP Laminates}

The FRP laminates will be modeled using shell elements known as SHELL99 in ANSYS. The shell element takes into account the orthotropic material properties. This element is capable of inputting material properties in a local coordinate system in which the primary axis can be directly aligned parallel to the key FRP fibers $[37,46]$.

\section{Steel Supports}

Solid brick elements designated as SOLID45 in ANSYS to model steel plates or end supports as bonding agents [15]. SOLID45 element has eight nodes with three degrees of freedom at each node and three translations. These solid brick elements also simulate nonlinear effects including stress stiffening, creep, swelling and plasticity.

\section{Steel Rebar's-Concrete Bonding}

The bond interface (bond-slip behavior) of steel rebar's and concrete will be simulated using spring elements known as COMBIN14 in ANSYS [23].

\section{FRP System and Concrete Surfaces Bonding}

The interface between FRP laminates and concrete will be simulated using contact elements such cohesive element designated as INTER205 in ANSYS [47].

\section{Meshing}

In order for the current study to obtain actual results from the SOLID65 element during simulation, a mesh is usually recommended [48]. The meshing element in ANSYS will be used to mesh the model beam in a manner that it can be recognized as a square element measuring 10mm (refer with: Fig. 3).

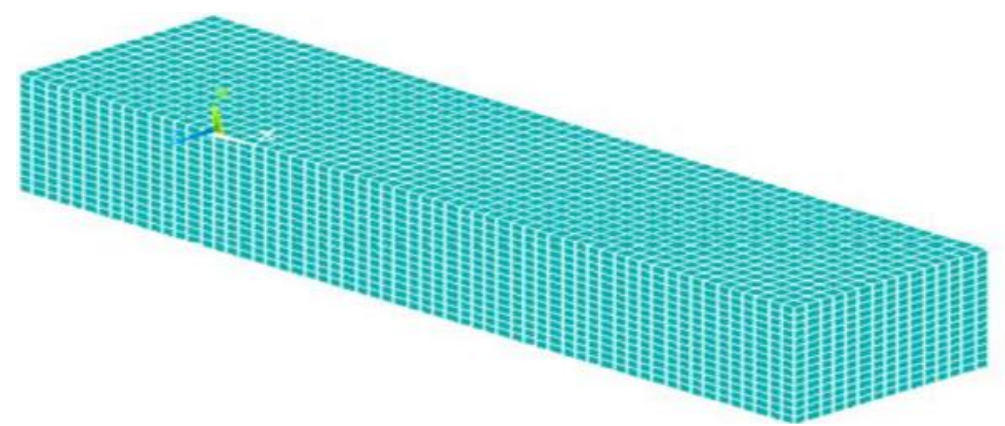

Figure 3. Meshed beam model 


\section{Considerations for Loadings and Boundary Conditions}

In order to accurately represent the experimental setup, realistic boundary conditions for the FE models were incorporated. The supports were modeled as rollers at each opposite ends and the external loads were applied as concentrated forces at 1500mm from the supports from both ends as shown in Fig. 4.

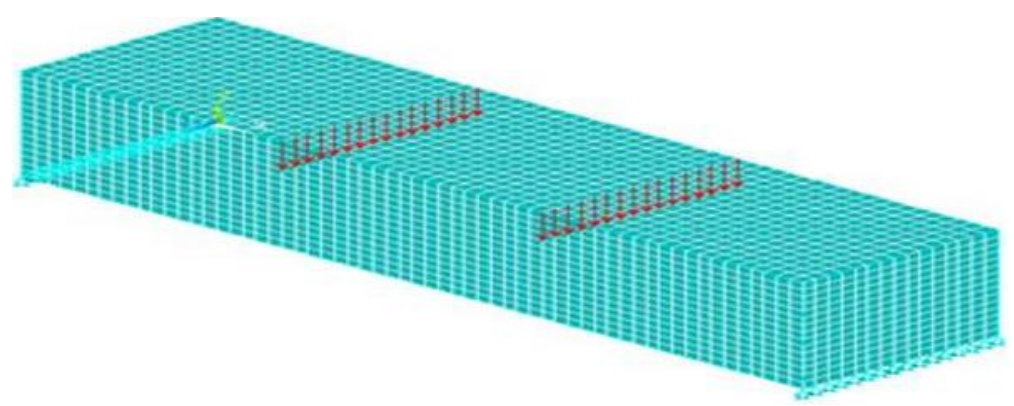

Figure 4. Boundary and loading conditions for the FE model

\section{Convergence and Failure Criteria}

The developed FE models will be analyzed by applying the dynamic load incrementally using the ANSYS software. The load will be applied incrementally, at an interval of $10 \mathrm{kN}$, at two points dividing the length of the beam into three parts (refer with: Fig. 1), until failure using the load steps and sub-steps commands in ANSYS [49]. Different types of information will be collected under the following aspects about the response and behavior of the five beams: stress distribution, deformation behavior, load-displacement, failure modes and crack patterns.

\section{RESULTS AND DISCUSSIONS}

Three cases of RC beams will be considered as outlined under methodology. The first case will be the reference or the control beam and no strengthening will be used. In the remaining cases, one layer and two layers of CFRP will be used, respectively, in the simulation of the beam. Following the description above, the results are expected to appear as discussed below.

\section{Deflection and Failure mode}

It will be noticed that using CFRP decreases deflection when subjected to an explosion. CFRP sheets are likely to improve the elasticity modulus, the tensile strength and the maximum strain of the RC beam. Increasing the number of layers of CFRP is expected to reduce the number and propagation of cracks (or increase the rate of reduction in deflection) on the RC beam to a certain point beyond which any additional layers of CFRP sheets will not have any significant influence. This means that, at this point, the failure mode or the rate of reduction in deflection will most likely be governed by the bond strength between concrete and the CFRP surfaces and not necessarily by additional CFRP layers. It is anticipated that if this bond strength will be exceeded, the number of CFRP layers will not have any significant influence.

\section{Energy Absorption}

It is expected that as the number of CFRP layers is increased, the energy dissipation will increase in equal measure or will cause reduction of displacement of the mid beams. The CFRP sheets will absorb energy or shock from the explosion. The maximum force generated in the CFRP sheets decreases as the number of layers of CFRP sheet increases. Similar to the deflection trend, the more the number of CFRP layers, the less the rate of increase in dissipated energy. Increasing the CFRP layers for external reinforcing is most likely to cause negligible differences in the beam displacement while at the same time leading to a decrease in the maximum force.

\section{Tensile Damage}

The beam without CFRP strengthening is expected to show high tensile damage while the beam with two layers of CFRP is expected to reveal less propagation of cracks indicating less tensile damage. It is expected that using one layer of CFRP will increase the required combination of pressure and impulse to cause the same tensile damage as the RC beam without strengthening. Hence, more explosion charge will be required or detonated for the same damage level. However, it is also expected that increasing the number of CFRP laminate beyond a certain point will not be necessarily efficient in enhancing the capacity for RC beams subjected to blast loading but rather the bond between concrete and CFRP surfaces. 


\section{Tensile Stress}

It is expected that the maximum values of tensile stress for the transverse reinforcing bars in some blast scenarios for the strengthened beams will be higher compared to blast scenarios of un-strengthened RC beams. This is likely to be so due to the erosion of the concrete in un-strengthened beam which will result in the release of stress in ties since the stress in ties is primarily due to the presence of concrete, while, the strengthened $\mathrm{RC}$ beam being a confined concrete, the erosion is less and thus the stress in ties is higher. As a result, the un-strengthened RC beam will fail due to direct shear as a result of the proximity of the blast. The retrofitting of RC beam is likely to improve the overall blast resisting capacity by increasing the shear capacity of the RC beam.

\section{Debonding}

Debonding is expected to start from the end of CFRP strips, in which flexural cracks that introduce drastic variations in strain level in CFRP strips are most prominent. It is expected that the RC beams strengthened with CFRP will undergo a failure mechanism known as debonding. The CFRP fracture is expected to fail with steel yielding to increase strain utilization. This failure mode is expected at the side-bonded, CFRP-concrete interface. Equally, premature debonding modes such as concrete cover separation is anticipated to occur along the internal steel level, whereas, plate-end debonding, shear, and flexure-induced debonding are expected to occur at the concrete-CFRP interface. However, the near surface mounted bars or strips are expected to reduce adhesion between the strip and adhesives. As a result, the reduction in adhesion is likely to induce the formation of longitudinal cracks in the adhesive layer due to the radial component of bond stress and the occurrence of progressive failure in the CFRP-adhesive interface. On the other hand, cohesive shear failure within the adhesive is expected to occur in the stiff concrete since the adhesive stress is likely to exceed the tensile strength limit. Similarly, the CFRP-adhesive-concrete bonds are expected to be susceptible to freezethaw conditions in moist environments and are likely to cause corrosion and contraction/expansion stress resulting in the formation of micro-cracks which then propagate toward CFRP laminates-concrete interface, eventually causing debonding. Debonding within CFRP is expected to occur at high temperatures leading to the loss of tensile strength.

\section{Rupture of CFRP}

In RC beams strengthened with a single layer of CFRP, a maximum CFRP rupture strain is expected along the horizontal direction on the beam compared with the vertical directions. This is likely to occur due to the development of excessive diagonal shear cracks under peak load or ultimate loading. It is also expected that the possible utilization of strain and the brittle rupture of CFRP layers is will reduce in RC beams strengthened with double layer sheet of CFRP at levels below their effective stress. The use of multiple layers of CFRP is expected to effectively prevent premature fracture with the help of effective bond stress distress along the width of concrete.

\section{CONCLUSION}

a) CFRP is most likely to possess high tensile strength that is expected to double the ultimate strength of RC beams compared to RC beam without CFRP strengthening.

b) Using CFRP material to strengthen RC beams will reduce the degree of damage of the RC beams when subjected to blast loads. The use of CFRP increases the required explosive mass that is needed to cause the same damage to the RC beam which is not retrofitted or strengthened.

c) As the number of layers of CFRP increases the mid-span deflection for RC beams, with two layers of CFRP was decrease compared with a beam without CFRP. However, it should be noted that the decrease in deflection (or failure mode) was be more likely to be governed not by further increasing the number of layers of CFRP from two to three or four but by the bond between CFRP surfaces and concrete.

d) An RC beam was most likely resist higher blast load in the presence of CFRP material. Strengthening the beam with two layers of CFRP is likely to increase the explosive mass required to cause damage by twice compared to an RC beam without CFRP.

e) Using CFRP sheets in RC beams was likely increase the absorbed energy of the beam. Higher absorption has been associated with a decreased number and propagation of cracks.

f) Using adhesives is likely to reduce debonding, however, increasing the number of layers of adhesives is expected to be sufficient to resist all types of debonding.

\section{ACKNOWLEDGEMENT}

The authors would like to acknowledge Universiti Malaysia Pahang for providing financial support under University Research Grant, RDU1903146 and Faculty of Civil Engineering Technology for facilities. 


\section{REFERENCES}

[1] H. Hao, Y. Hao, J. Li and W. Chen, Review of the current practices in blast-resistant analysis and design of concrete structures. Advances in Structural Engineering, 19(8),1193-1223, 2016.

[2] W. Bounds, Design of Blast-Resistant Buildings in Petrochemical Facilities, $2^{\text {nd }}$ Edition. Journal of The Journal of Civil Engineering, 66(7), 1-300, 2018.

[3] D.S.J. Jones and S. A. Treese, Off-Site Facilities for Petroleum Processing. In: Treese S., Jones D., Pujado P. (eds) Handbook of Petroleum Processing. Springer, Cham, 2014. https://doi.org/10.1007/978-3-319-05545-9_18-1.

[4] S. Parkash, Refinery Off-Site Facilities and Utility Systems. Refining Processes Handbook. Burlington: Gulf Professional Publishing, pp.270-307, 2003.

[5] R.M.M. Ali, Performance Based Design of Offshore Structures Subjected To Blast Loading, Ph.D. dissertation, Department of Civil and Environmental Engineering, Imperial College London, 2007.

[6] M.M. Yussof, J.H. Silalahi, M.K. Kamarudin, P.S. Chen and G.A. Parke, Numerical evaluation of dynamic responses of steel frame structures with different types of haunch connection under blast load. Applied Sciences, 10(5), 1815, 2020.

[7] Task Committee on Blast-Resistant Design of the Petrochemical Committee, "Design of Blast-Resistant Buildings in Petrochemical Facilities (2nd Ed.)", American Society of Civil Engineers, 2010.

[8] R. Kishore, N.N. ZIA and R.A. MUSLIM, Strengthening of Reinforced Concrete Beams Using CFRP Laminates, 2016.

[9] ASCE, Design of Blast-Resistant Buildings in Petrochemical Facilities, 2nd ed.; American Society of Civil Engineers: Reston, VA, USA, 2010.

[10] D.P. Nolan, Handbook of fire and explosion protection engineering principles: for oil, gas, chemical and related facilities, William Andrew, 2014.

[11] M.Z. Naser, R.A. Hawileh, J.A. Abdalla, Modeling Strategies of Finite Element Simulation of Reinforced Concrete Beams Strengthened with FRP: A Review. Journal of Composites Science, 5(1), 19, 2021.

[12] A. Siddika, M.A. Al Mamun, R, Alyousef and Y.M. Amran, Strengthening of reinforced concrete beams by using fiberreinforced polymer composites: A review. Journal of Building Engineering, 25, 100798, 2019.

[13] N.Z. Hassan, A.G. Sherif and A.H. Zamarawy, Finite element analysis of reinforced concrete beams with opening strengthened using FRP. Ain Shams Eng. J. 8, 531-537, 2017.

[14] R.A. Hawileh, J.A. Abdalla and M.Z. Naser, "Modeling the Shear Strength of Concrete Beams Reinforced with CFRP Bars under Unsymmetrical Loading." Mechanics of Advanced Materials and Structures. pp. 1-8, 2018. (https://doi.org/10.1080/15376494.2018.1432803).

[15] R.A. Hawileh, M.Z. Naser and J.A. Abdalla, Finite element simulation of reinforced concrete beams externally strengthened with short-length CFRP plates. Compos. Part B Eng., 45, 1722-1730, 2013.

[16] V. Gribniak, I. Misiunait ${ }^{-}$e, A. Rimkus, A. Sokolov and A. Šapalas, Deformations of FRP-Concrete Composite Beam: Experiment 'and Numerical Analysis. Appl. Sci., 9, 5164, 2019

[17] R. Hawileh, J.A. Abdalla, M.Z. Naser and M. Tanarslan, Finite element modeling of shear deficient RC beams strengthened with NSM CFRP rods under cyclic loading. ACI Spec. Publ., 301, 1-18, 2015.

[18] D. Sorin, B. Corneliu, B. Catalin, D. Daniel, F. Constantin, C. Liliana, P. Vasile and G. Aurelian, Carbon Fiber Reinforced Polymers Used for Strengthening of Existing Reinforced Concrete Structures. Materiale Plastice, vol. 55, Iss. No. 4. pp 536540, 2018.

[19] M. Goldstone, CFRP Strengthening of Reinforced Concrete Beams for Blast and Impact Loads. Faculty of Engineering, University of Wollongong, 2012.

[20] J. Tarigan, R. Meka and Nursyamsi, The usage of carbon fiber reinforcement polymer and glass fiber reinforcement polymer for retrofit technology building, IOP Conf. Series: Earth and Environmental Science 126, 012024, 2018.

[21] T.H. Almusallam and Y.A. Al-Salloum, Durability of GFRP rebars in concrete beams under sustained loads at severe environments. Journal of composite materials, 40(7), 623-637, 2006.

[22] R.A. Hawileh and M.Z. Naser, Thermal-stress analysis of RC beams reinforced with GFRP bars. Composites Part B: Engineering, 43(5), 2135-2142, 2012.

[23] R.A. Hawileh, Finite element modeling of reinforced concrete beams with a hybrid combination of steel and aramid reinforcement. Mater. Des., 65, 831-839, 2015.

[24] A. Lapko and M. Urbański, Experimental and theoretical analysis of deflections of concrete beams reinforced with basalt rebar. Archives of Civil and Mechanical Engineering, 15(1), 223-230, 2015.

[25] O. Rabinovitch and Y. Frostig, Experiments and analytical comparison of RC beams strengthened with CFRP composites. Composites Part B: Engineering, 34, 663-677, 2003.

[26] A. Jahami, Y. Temsah and J. Khatib, The efficiency of using CFRP as a strengthening technique for reinforced concrete beams subjected to blast loading. International Journal of Advanced Structural Engineering, 11(4), 411-420, 2019.

[27] D. Lavorato, C. Nuti and S. Santini, Experimental investigation of the shear strength of RC beams extracted from an old structure and strengthened by carbon FRP U-strips. Applied Sciences, 8(7), 1182, 2018.

[28] J.Y. Lee, H.O. Shin, K. H. Min and Y.S. Yoon, Flexural assessment of blast-damaged RC beams retrofitted with CFRP sheet and steel fiber. International Journal of Polymer Science, 2018. 
[29] M. Shooshtari and H. Gomar, Retrofit of reinforced concrete structures by CFRP/GFRP sheets against blast load. Mathematical Models in Engineering, 3(1), 49-57, 2017.

[30] Camille A. P.E. Issa, F. ASCE and A. Abdo AbouJouadeh, Carbon Fiber Reinforced Polymer Strengthening of Reinforced Concrete Beams: Experimental Study (2004).

[31] W. Bounds, Design of Blast-Resistant Buildings in Petrochemical Facilities. American Society of Civil Engineering, 2010.

[32] L.A. Louca and R.M. Ali, Improving the Ductile Behaviour of Offshore Topside Structures Under Extreme Loads. Eng. Struct., 30, 506-521, 2008.

[33] O. Shallan, A. Eraky, T. Sakr and S. Emad, Response of building structures to blast effects. International journal of engineering and innovative technology, 4(2):167-75, 2014.

[34] L.Y. Jiang, G.J. Liu and X.D. Sun, Mechanic Behavior Analysis of Connection with Haunch under Single and Cyclic Load. Appl. Mech. Mater., 105-107, 848-852, 2011.

[35] Y. Liu, B. Zwingmann and M. Schlaich, Nonlinear progressive damage analysis of notched or bolted fibre-reinforced polymer (FRP) laminates based on a three-dimensional strain failure criterion. Polymers, 6, 949-976, 2014.

[36] S. Kim and R.S. Aboutaha, Finite element analysis of carbon fiber-reinforced polymer (CFRP) strengthened reinforced concrete beams. Comput. Concr., 1, 401-416, 2004.

[37] R. Shrestha, S.T. Smith and B. Samali, Finite element modelling of FRP-strengthened RC beam-column connections with ANSYS. Comput. Concr., 11, 1-20, 2013.

[38] D.I. Kachlakev, T.H. Miller, T. Potisuk, S.C. Yim and K. Chansawat, Finite element modeling of reinforced concrete structures strengthened with FRP laminates (No. FHWA-OR-RD-01-XX). Oregon. Dept. of Transportation. Research Group, 2001.

[39] Ameli, H.R. Ronagh and P.F. Dux, Behavior of FRP strengthened reinforced concrete beams under torsion. J. Compos. Constr., 11, 384-390, 2007.

[40] J. Zeng, Y. Guo, L. Li and W. Chen, Behavior and Three-Dimensional Finite Element Modeling of Circular Concrete Columns Partially Wrapped with FRP Strips. Polymers, 10, 253, 2018.

[41] H. Yu, Y.L. Bai, J.G. Dai and W.Y. Gao, Finite element modeling for debonding of FRP-to-concrete interfaces subjected to mixed-mode loading. Polymers, 9, 438, 2017.

[42] D. Tjitradi, E. Eliatun and S. Taufik, 3D ANSYS numerical modeling of reinforced concrete beam behavior under different collapsed mechanisms. International Journal of Mechanics and Applications, 7(1), 14-23, 2017.

[43] C. A. Neagoe, Concrete beams reinforced with CFRP laminates, Master's thesis, Universitat Politècnica de Catalunya, 2011.

[44] E. Madenci and I. Guven, The finite element method and applications in engineering using ANSYS®. Springer, 2015.

[45] K. Willam and E. Warnke, Constitutive model for the triaxial behavior of concrete. Proc. Intl. Assoc. Bridge Structl. Engrs., 19, 1-30, 1975.

[46] L.V.H. Bui, B. Stitmannaithum and T. Ueda, Mechanical performances of concrete beams with hybrid usage of steel and FRP tension reinforcement. Comput. Concr., 20, 391-407, 2017.

[47] B.M. Lazzari, A.C. Filho, P.M. Lazzari and A.R. Pacheco, Using the element-embedded rebar model in ansys to analyze reinforced concrete beams. Comput. Concr., 19, 347-356, 2017.

[48] N.A. Hamid, M.H. Ismail, A. Ibrahim and A. Adnan, Finite element analysis of smart reinforced concrete beam with super elastic shape memory alloy subjected to static loading for seismic mitigation. InAIP Conference Proceedings 2018 May 9 (Vol. 1958, No. 1, p. 020033). AIP Publishing LLC.

[49] ANSYS, A Finite Element Computer Software and User Manual for Nonlinear Structural Analysis, ANSYS-Release Version 14.5., Inc. Canonsburg, PA, 2013. 